\title{
BMJ Open Occupational disparities in survival in Korean women with cancer: a nationwide registry linkage study
}

\author{
Hye-Eun Lee (D) ,1,2 Eun-A KIM (D) , ${ }^{3}$ Masayoshi Zaitsu, ${ }^{2,4}$ Ichiro Kawachi $^{2}$
}

To cite: Lee H-E, KIM E-A, Zaitsu M, et al. Occupational disparities in survival in Korean women with cancer: a nationwide registry linkage study. BMJ Open 2020;10:e039259. doi:10.1136/ bmjopen-2020-039259

- Prepublication history and additional material for this paper are available online. To view these files, please visit the journal online (http://dx.doi. org/10.1136/bmjopen-2020039259).

Received 14 April 2020 Revised 15 June 2020 Accepted 22 July 2020

\section{Check for updates}

(c) Author(s) (or their employer(s)) 2020. Re-use permitted under CC BY-NC. No commercial re-use. See rights and permissions. Published by BMJ.

${ }^{1}$ Korea Institute of Labor Safety and Health, Seoul, Republic of Korea

${ }^{2}$ Department of Social and Behavioral Sciences, Harvard T.H. Chan School of Public Health, Boston, Massachusetts, USA

${ }^{3}$ Occupational Safety and Health Research Institute, Korea Occupational Safety and Health Agency, Ulsan, Republic of Korea ${ }^{4}$ Department of Public Health, Graduate School of Medicine, The University of Tokyo, Tokyo, Japan

Correspondence to

Dr Eun-A KIM;

toxneuro@gmail.com

\section{ABSTRACT}

Objectives We sought to examine occupational disparities in survival among Korean women diagnosed with cancer. Design Population-based, registry-linkage study. Setting South Korea.

Participants Our study population comprised female workers registered in the Korean national employment insurance programme during 1995-2000 and diagnosed with cancer between 1995 and 2008. A total of 61110 women with cancer diagnoses was included in analysis. The occupation was categorised into four groups: (1) managers, professionals and technical workers, (2) clerks, (3) service/sales workers and (4) blue-collar workers. Primary and secondary outcome measure Study population were linked to the national death registry until 2009. HRs for mortality adjusting for age and year of diagnosis were calculated in the study sample and subgroups with 10 specific cancer sites including thyroid, breast, stomach, cervix, colon or lung cancer using managers, professionals and technical workers as the reference.

Results Women in service/sales (HR 1.25, 95\% Cl 1.15 to 1.35) and blue-collar occupations (HR $1.34,95 \% \mathrm{Cl} 1.25$ to 1.44) had poorer survival for all cancer sites combined, while blue-collar workers showed poorer survival for lung (HR 1.41, 95\% Cl 1.14 to 1.77), breast (HR 1.28, 95\% Cl 1.06 to 1.54 ), cervical cancer ( $\mathrm{HR} 1.42,95 \% \mathrm{Cl} 1.02$ to 2.06) and non-Hodgkin's lymphoma (HR $1.69,95 \% \mathrm{Cl}$ 1.09 to 2.77 ) compared with women in professional and managerial positions.

Conclusion We found substantial and significant inequalities in overall survival by the occupational group among Korean women with cancer, even in the context of universal access to cancer screening and treatment.

\section{INTRODUCTION}

Cancer is a leading cause of death in South Korea, with more than 200000 new cancer cases diagnosed each year. ${ }^{1}$ Significant socioeconomic inequalities in cancer survival have been previously found in many countries despite universal access to healthcare. ${ }^{2-4}$ As an indicator of socioeconomic status (SES), the occupation has been widely used, especially in European countries. ${ }^{5}$ However, studies on occupational disparities in cancer survival remain sparse in the Asian context. ${ }^{6-8}$ These studies reported significantly poorer survival

\section{Strengths and limitations of this study}

This is the first study to investigate occupational disparities in overall survival among Korean women with cancer.

- Using a large and representative workers cohort and cancer registry data enabled us to analyse a number of specific cancer sites with a sufficient number of cases, and to generalise the results to the population of working women in Korea.

- Due to our longitudinal follow-up design, reverse causation of cancer diagnosis resulting in a change in occupation can be ruled out.

- Due to the lack of information on important covariates, we could not evaluate the contribution of mediating variables between occupation and survival in patients with cancer.

for pancreatic cancer among blue-collar workers and service workers compared with white-collar workers, as well as worse survival for bladder cancer among professionals and managers, sales and service workers, construction workers and workers in manufacturing compared with clerical workers in Japan. ${ }^{6}{ }^{8}$ A previous Korean study showed that men in service/sales and blue-collar occupations had poorer survival for oesophagus, stomach, colorectal, liver, larynx, lung, prostate, thyroid cancer and non-Hodgkin's lymphoma compared with men in professional and managerial jobs. ${ }^{7}$

Cancer incidence, mortality and survival are key measures of cancer burden, and the use of all three measures can provide a more comprehensive picture in assessing progress in the context of a national cancer control strategy. ${ }^{9}$ According to a previous Korean study of occupational disparities in cancer incidence, men showed substantial occupational disparities in lung and liver cancer incidence, but women in professional and managerial jobs showed a significantly higher incidence of all cancers combined and selective cancers including breast, corpus uteri, ovary or thyroid cancer, compared with 
women in service and sales or blue-collar jobs. ${ }^{10}$ However, cancer mortality was significantly higher among women in elementary occupations than among professionals and managers. ${ }^{11}$

Based on these findings, we hypothesised that occupations in lower social positions would be linked to poorer survival in female cancer patients. Occupation-along with educational attainment and income-is considered one of the fundamental axes of social stratification. ${ }^{5}$ Occupation influences an individual's access to resources (such as income, savings, retirement pension), access to health insurance, access to paid leave and child care, access to powerful social connections ('social capital'), as well as prestige and status in society.

Broadly speaking, the mechanisms linking SES disparities in cancer survival include factors that operate across the cancer spectrum, including stage of diagnosis, access to treatment modalities and treatment adherence. ${ }^{12}$ For example, professional and managerial women may participate in cancer screenings more frequently than bluecollar job women. A number of studies have also pointed to differences in access to treatment between different socioeconomic groups. ${ }^{13}$ Also, patients' characteristics such as comorbidity, nutritional status, social support and treatment adherence behaviour might influence disparities in cancer survival. ${ }^{13}$ According to a Danish populationbased study, women in higher occupational social class experienced a higher incidence of breast cancer than lower occupational social class women, but the pattern was reversed for breast cancer survival. ${ }^{14}$ Earlier diagnosis and better treatment are determinants of better survival of breast cancer among women in higher occupational social class, while reproductive factors such as late age at first birth and fewer children can explain their higher incidence. Korean data also showed a higher incidence of breast cancer among managers and professionals than among blue-collar workers. ${ }^{10}$

In South Korea, several studies have been published on socioeconomic disparities in cancer-specific or overall survival in cancer patients, but most of these studies did not show sex-stratified results and occupation was not used as an indicator to measure SES. ${ }^{15-17}$ A previous study limited in a local area performed sex-stratified analysis, however, the SES indicator used was ecological, based on an area-level deprivation index. ${ }^{18}$

Thus, in the present study, we aimed to investigate occupational disparities on survival among Korean working women with cancer using large longitudinal data.

\section{METHODS}

\section{Data source and study population}

Our data were derived from a cohort of Korean workers, who were covered by the national Employment Insurance programme (1995-2000). The Korean Employment Insurance system started in 1995, covering companies with more than 70 employees, and was expanded to cover all employed workers in the private sector

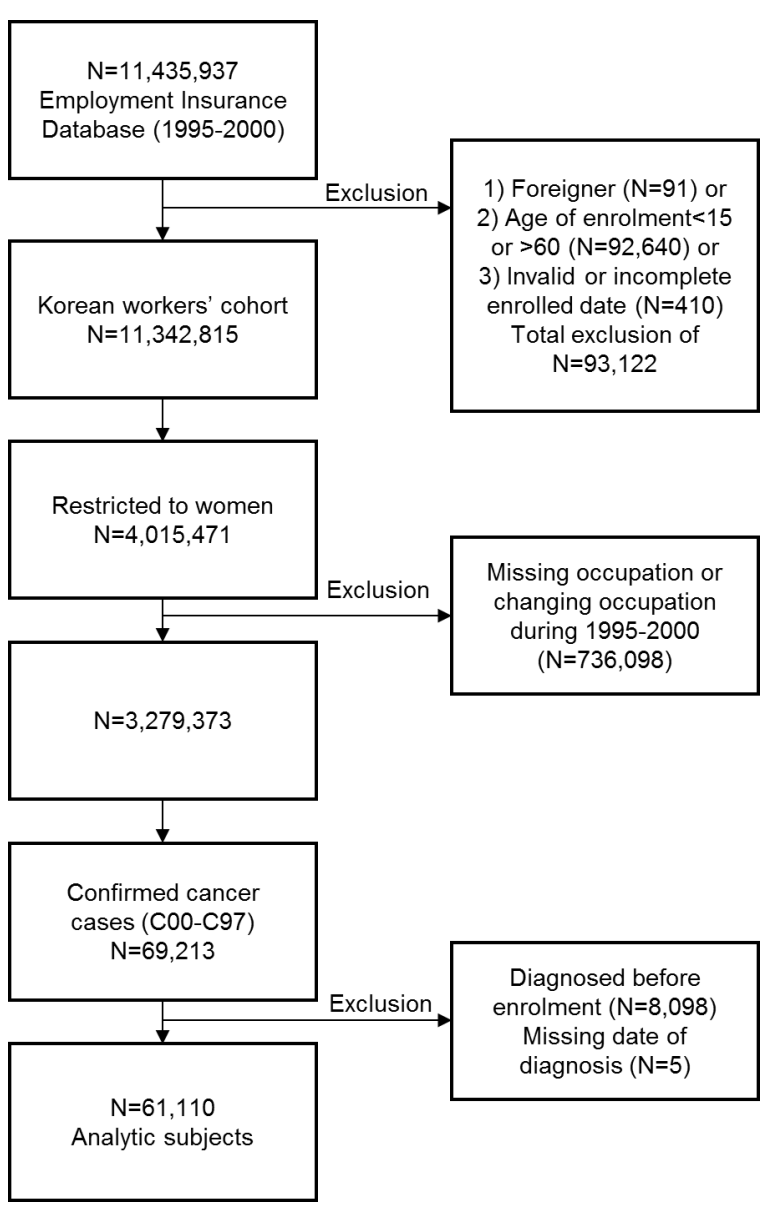

Figure 1 Selection of study population.

regardless of company size since 1998 . Thus, the data of Employment Insurance did not include employers, selfemployed, unpaid family workers and employees in the public sector. The database included 11435937 workers. We excluded foreign workers, workers under the age of 15 years or $>60$ years at baseline (on the date of hire), and workers with invalid or incomplete enrolment dates. We restricted the study sample to women with valid occupational information and women who stayed in the same occupation between 1995 and 2000. After establishing the workers' dataset, cancer cases were confirmed by matching workers to the Korea Central Cancer Registry (1995-2008). Diagnoses of malignant neoplasms (C00C97) based on the International Classification of Disease, 10th Revision, was used to code specific cancer sites. Individuals diagnosed with cancer before enrolment in the workers' cohort or having an incomplete or missing date of diagnosis were excluded from the analysis. As a result, 61110 female cancer cases were used for analysis (figure 1).

The study population was followed via linkage to the death registry operated by the Korea National Statistical Office (KNSO) between 1995 and 2009. The coverage of the death registry can be regarded complete because all deaths in Korea are reported to the KNSO by law. 


\section{Classification of occupations}

To classify occupations, we used the information on occupation from the employment insurance programme coded using the Korean Standard Classification of Occupations (KSCO) between 1995 and 2000. This classification corresponds to the International Standard Classification of Occupations. ${ }^{11}$ To compare between occupations with a sufficient number of cases, we collapsed the nine occupational categories into four groups as follows: (1) group 1 (managers, professionals and technical workers): KSCO1 (legislators, senior officials and managers), KSCO2 (professionals) and KSCO3 (technicians and associate professionals), (2) group 2 (clerks): KSCO4 (clerks), (3) group 3 (service and sales workers): KSCO5 (service workers and sale workers), (4) group 4 (blue-collar workers): KSCO6 (agricultural, forestry and fishery workers), KSCO7 (craft and related trades workers), KSCO8 (plant and machine operators and assemblers) and KSCO9 (elementary occupations). ${ }^{11}$ Based on average income and education distribution, managers, professionals and technical workers was considered as high SES occupation, and service/sales workers and blue-collar workers were considered as low SES occupations. ${ }^{10}$

\section{Statistical analysis}

We used overall survival as an outcome which was defined as the time interval between the date of cancer diagnosis and the date of death from any cause or the date of the end of follow-up (31 December 2009), whichever came first. Patients with cancer who were not matched with death registry were considered alive and were censored at the end of study. The average follow-up was 4.2 person-years.

Cox proportional hazards models were used to calculate HRs and 95\% CIs adjusting for age and year of diagnosis as continuous variables to investigate the disparities across occupational groups. As screening and treatment have improved over time for many cancer sites, we adjusted for year of diagnosis in the Cox hazard models. The outcomes analysed included all cancer sites combined (C00-C97) as well as the 10 most common cancer sites which had sufficient cases. Proportional hazards assumptions were met. Survival curves are shown for all cancer sites combined as well as specific sites that showed statistically significant disparities by occupation. For sensitivity analyses, to assure enough follow-up period to detect survival differences across occupations, we performed the analyses among a restricted sample with a follow-up period for 5 years or more, which comprised 22849 women diagnosed with cancer between 1995 and 2003.

\section{Patient or public involvement}

No patient involved.

\section{RESULTS}

Table 1 summarises the characteristics of female cancer cases used for analysis. Among a total of 61110 cancer
Table 1 Characteristics of the study population

\begin{tabular}{lll}
\hline & $\mathbf{N}$ & $\%$ \\
\hline Total & 61110 & 100.0
\end{tabular}

Age of diagnosis

\begin{tabular}{lrr}
$<20$ & 72 & 0.1 \\
\hline $20-29$ & 5245 & 8.6 \\
$30-39$ & 15579 & 25.5 \\
$40-49$ & 17216 & 28.2 \\
$50-59$ & 15005 & 24.6 \\
\hline $60-$ & 7993 & 13.1 \\
\hline Year of diagnosis & & \\
1995-1999 & 6654 & 10.9 \\
\hline $2000-2004$ & 21861 & 35.8 \\
\hline $2005-2008$ & 32595 & 53.3 \\
\hline Occupational group & & \\
\hline $\begin{array}{l}\text { Managers, professionals and } \\
\text { technical workers }\end{array}$ & 5822 & 9.5 \\
Clerks & & \\
\hline Service and sales workers & 7524 & 12.3 \\
\hline Blue-collar workers & 32402 & 53.0
\end{tabular}

Vital status

\begin{tabular}{|c|c|c|}
\hline Alive & 47569 & 77.8 \\
\hline \multirow[t]{2}{*}{ Dead } & 13541 & 22.2 \\
\hline & N (death) & $\%$ \\
\hline \multicolumn{3}{|l|}{ Cancer sites } \\
\hline $\begin{array}{l}\text { Lip, oral cavity and pharynx } \\
\text { (C00-C14) }\end{array}$ & $579(143)$ & 0.9 \\
\hline Oesophagus (C15) & $59(31)$ & 0.1 \\
\hline Stomach (C16) & $6918(2453)$ & 11.3 \\
\hline $\begin{array}{l}\text { Colon, rectosigmoid junction, } \\
\text { rectum }(C 18-C 20)\end{array}$ & $4721(1315)$ & 7.7 \\
\hline $\begin{array}{l}\text { Liver and intrahepatic bile } \\
\text { ducts (C22) }\end{array}$ & $2026(1483)$ & 3.3 \\
\hline $\begin{array}{l}\text { Gallbladder, other and } \\
\text { unspecified parts of biliary } \\
\text { tract }(\mathrm{C} 23-\mathrm{C} 24)\end{array}$ & $850(562)$ & 1.4 \\
\hline Pancreas (C25) & $605(497)$ & 1.0 \\
\hline Larynx (C32) & $33(6)$ & 0.1 \\
\hline $\begin{array}{l}\text { Trachea, bronchus and lung } \\
\text { (C33-C34) }\end{array}$ & 2077 (1394) & 3.4 \\
\hline Mesothelioma (C45) & $24(17)$ & 0.0 \\
\hline Breast (C50) & $12673(1541)$ & 20.7 \\
\hline Cervix uteri (C53) & $5271(783)$ & 8.6 \\
\hline Corpus uteri (C54) & $1416(175)$ & 2.3 \\
\hline Ovary (C56) & $1916(557)$ & 3.1 \\
\hline Kidney (C64) & $585(104)$ & 1.0 \\
\hline Bladder (C67) & $245(39)$ & 0.4 \\
\hline $\begin{array}{l}\text { Brain and other parts of central } \\
\text { nervous system (C70-C72) }\end{array}$ & $687(339)$ & 1.1 \\
\hline Thyroid gland (C73) & $15295(145)$ & 25.0 \\
\hline
\end{tabular}

Continued 


\begin{tabular}{lcc}
\hline Table 1 Continued & & \\
\hline & N (death) & $\%$ \\
\hline Hodgkin lymphoma (C81) & $79(13)$ & 0.1 \\
$\begin{array}{l}\text { Non-Hodgkin's lymphoma } \\
\text { (C82-C85, C96) }\end{array}$ & $1209(329)$ & 2.0 \\
Multiple myeloma (C90) & $198(112)$ & 0.3 \\
Leukaemia (C91-C95) & $1043(591)$ & 1.7 \\
\hline
\end{tabular}

cases, $28.2 \%$ were diagnosed with cancer in their 40 s. Around half of the study sample were employed in group 4 occupation (blue-collar workers). During the follow-up period, 13541 (22.2\%) women died. Among them, 12552 $(92.7 \%)$ died from cancer, $457(3.4 \%)$ died from noncancer and $532(3.9 \%)$ had missing information on the cause of death. The most frequently diagnosed cancer sites were thyroid $(25.0 \%)$, breast $(20.7 \%)$ and stomach $(11.3 \%)$. The cases of death were prevalent in stomach (2453), breast (1541), liver (1483), lung (1394) and colorectal cancer (1315).

HRs and 95\% CIs of overall survival using managers, professionals and technical workers as the reference group are presented in table 2 .

Blue-collar workers (HR 1.34, 95\% CI 1.25 to 1.44 ) and service/sales workers (HR 1.25, 95\% CI 1.15 to 1.35 ) showed poorer survival for all cancer sites combined compared with managers, professionals and technical workers. In terms of site-specific survival, blue-collar workers showed poorer survival for lung, breast, cervix uteri and non-Hodgkin's lymphoma, and both Bluecollar workers and service/sales workers showed significantly worse survival for thyroid cancer compared with managers, professionals and technical workers. Most other cancer sites (except for colorectal cancer) showed better survival for high SES occupation (managers, professionals and technical workers) as well, although the difference across occupational groups was not statistically significant.

Survival curves for all cancer combined and selected cancer sites by occupational groups are presented in figure 2. For all sites combined, the survival rate was highest for managers, professionals and technical workers, followed by clerks, service and sales workers, and blue-collar workers, in that order. Women in bluecollar jobs exhibited an obviously less favourable survival pattern than managers, professionals and technical workers for lung cancer and non-Hodgkin's lymphoma. Due to extremely high survival among patients with thyroid cancer, absolute differences in survival across occupational groups were not found.

The sensitivity analyses with subgroups with follow-up period for 5 years or more showed a similar pattern, although they had a wider CI due to decreased sample (online supplementary table S1).

\section{DISCUSSION}

To our knowledge, this is the first Korean study to comprehensively document occupational disparities in overall survival in a female working population diagnosed with cancer.

Previous studies of cancer survival in Korea have looked at disparities based on educational attainment, medical insurance status and area-level deprivation. ${ }^{15171920}$ Studies focusing on occupational disparities in cancer survival have been mostly limited to western settings. ${ }^{21-23}$ The HRs for lower survival (comparing white-collar workers to blue collar workers) are in a similar range to that found in our study, ranging from 1.0 to 1.4.

In the previous studies on socioeconomic cancer disparities, cancer of good prognosis showed a wider difference across SES groups. ${ }^{4717}$ Significant disparities in survival for breast, cervix uteri, thyroid cancer and non-Hodgkin's lymphoma found in the present study are in line with those previous studies. Our findings are consistent with the 'fundamental cause' theory of socioeconomic disparities advanced by Link and Phelan. ${ }^{24}$ According to this theory, socioeconomic disparities in health arise due to differential access to and deployment of a variety of flexible resources to benefit health, including not only money and knowledge, but also symbolic prestige and powerful social connection by people with higher SES. Thus, it can be hypothesised that strong socioeconomic gradients in survival would be observed for cancer sites with a good prognosis, that is, deaths which are highly preventable because effective modalities exist for early diagnosis and cure. On the other hand, fundamental cause theory predicts that SES disparities would be small or non-existent for cancers which have a uniformly poor prognosis and where effective screening is unavailable, where high SES people cannot use their resources.

Although lung cancer is often fatal for patients, it showed significant disparities as well in our data, showing a similar magnitude of difference across occupational groups with all cancer and cervix uteri cancer. As in other cancer sites, the main determinant of social disparities on lung cancer survival is known to be the stage at diagnosis and difference in treatment. ${ }^{25}$ Medical cost for lung cancer was third highest among all cancer sites in Korea. ${ }^{26}$ Although Korea has universal healthcare system under National Health Insurance or Medicaid programme, patients still had to copay $20 \%$ of the cost of cancer treatment until 2005 (covered by our follow-up period), in which year the policy of decreasing cancer patients' copayment to $10 \%$. In a previous Korean study, utilisation of inpatient and outpatient medical care of high-income patients with cancer was more frequent than low-income patients, and the patients with higher incomes tend to use services from major tertiary hospitals. ${ }^{27}$ Thus quality or differences in intensity of medical treatment could be a factor contributing to disparities in lung cancer survival. ${ }^{12}$

Social disparities in cancer survival can be also attributed to differences in stage at diagnosis. ${ }^{13}$ For the early detection of breast cancer and cervical cancer, the National 
Table 2 HRs and their 95\% Cls by occupational groups using Cox proportional hazard model

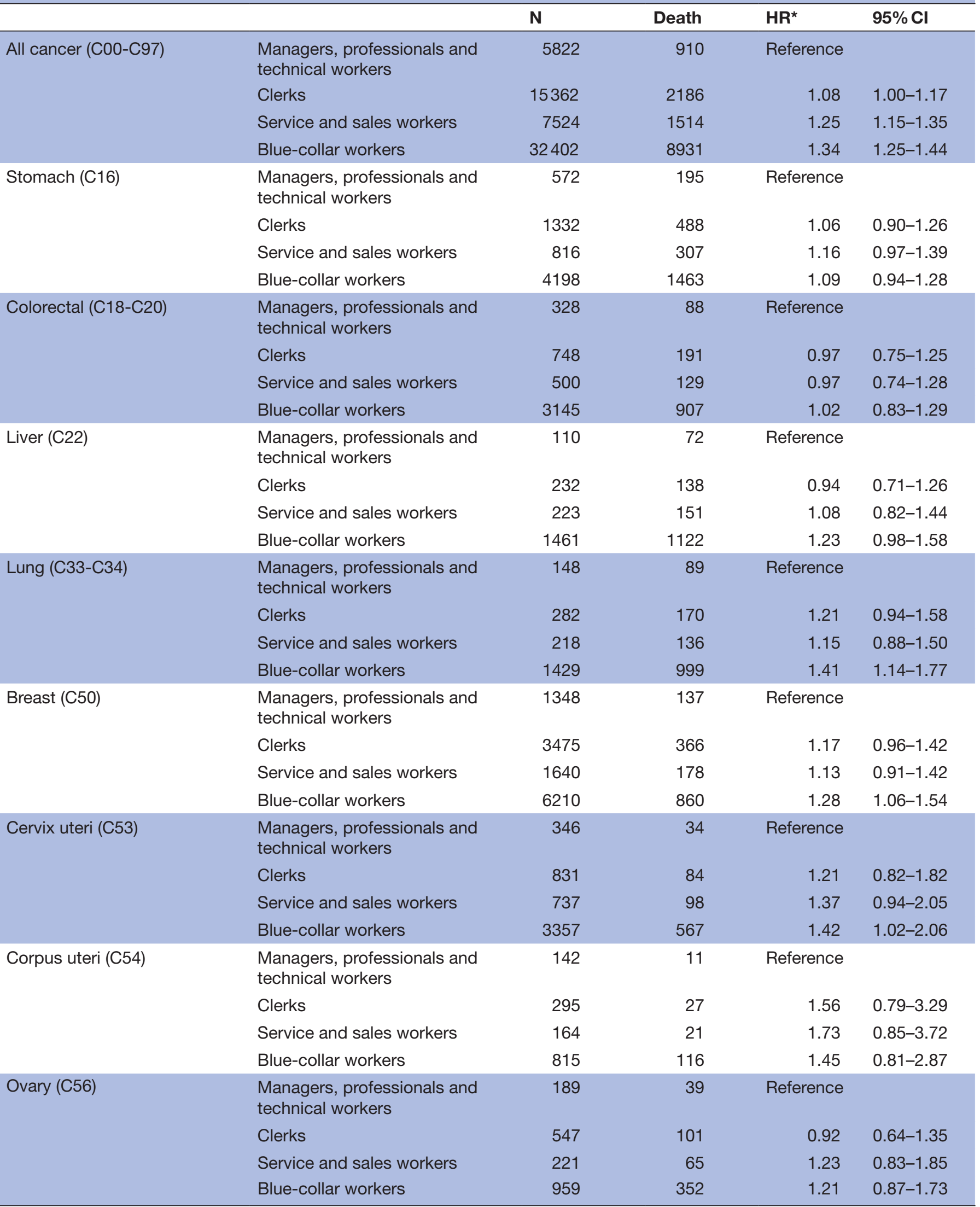


Table 2 Continued

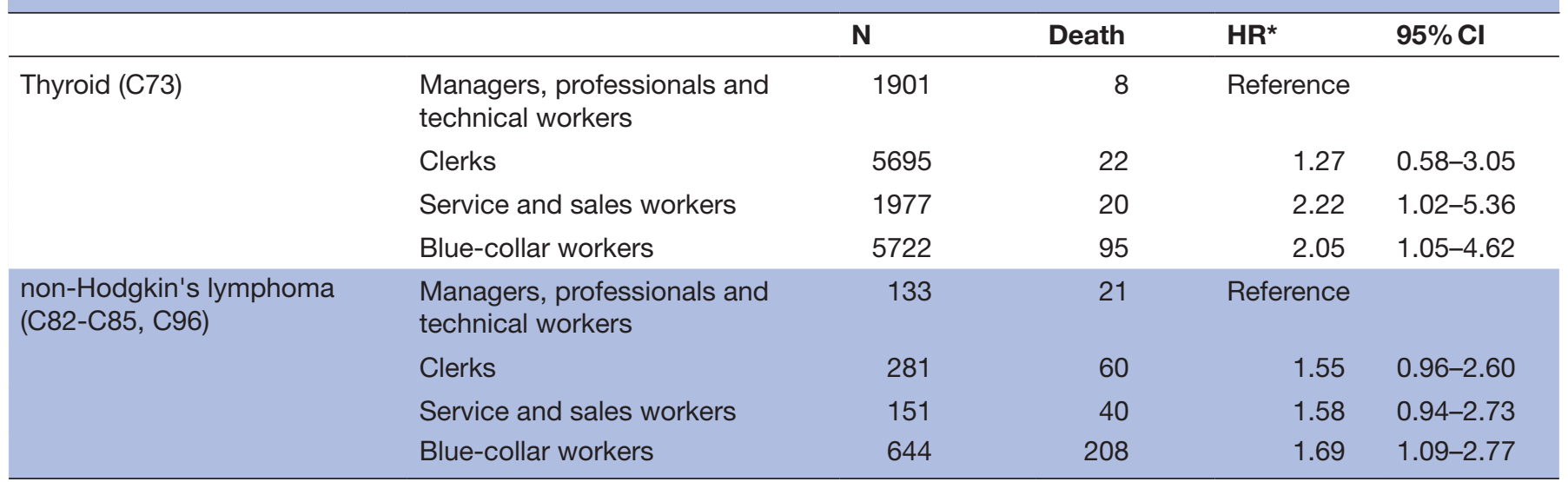

${ }^{*}$ Adjusted by age and year of diagnosis.

Cancer Screening Programme (NCSP) in Korea provides a mammogram and Pap smear every other year. ${ }^{28}$ Despite the free access to screening, income and educational disparities in the uptake of screening continue to persist; the percentage of breast cancer screened population within the past 2 years were $36.2 \%$ in the lowest income group and $42.9 \%$ in the highest income group; and for cervical cancer, $43.2 \%$ and $65.1 \%$, respectively, in $2005 .{ }^{29}$

Besides NCSP, private health check-ups including cancer screening of which cost is paid fully by the examined individual have been prevalent in Korea. Many companies, usually larger than medium size, pay the fee of these check-ups for employees as a part of the well-fare system. According to a previous study, private cancer screening participation rate was higher in female office workers than in manual workers. ${ }^{30}$ According to a previous Korean study, the lowest income group showed 1.35 times higher risk of advanced stage at the time of breast cancer diagnosis than the highest income group. ${ }^{31}$ The difference in stage at diagnosis could explain our finding of significant disparities in the survival of breast and cervical cancer.

Factors other than socioeconomic circumstances could potentially contribute to occupational disparities in cancer survival, such as occupational exposure to carcinogens. For example, some studies reported an association between occupational exposure and site-specific survival in sinonasal cancer, bladder cancer and non-Hodgkin's lymphoma. ${ }^{32-34}$ However, in a previous study on occupational disparities in cancer incidence, we did not find evidence of disparities in lung, bladder, or lymphohematopoietic cancer in women ${ }^{10}$; thus, we believe that the impact of occupational exposures on survival disparities observed in the current study is likely to be limited.

The current study found the widest relative gap for overall survival in thyroid cancer across occupational groups. There has been a sharp rise in thyroid cancer incidence in Korea, attributed to screening and overdiagnosis. ${ }^{35}$ Although survival was higher in high SES occupations with thyroid cancer, the incidence was also significantly higher in the same occupational group in the previous study with the same data source. ${ }^{10}$ Generally, thyroid cancer survival in Korean women is extremely high, more than $98 \%$ 5-year survival rate since $2001 .{ }^{1}$ Indeed, the absolute differences between occupational groups during the follow-up period were not observable in survival curves due to extremely low mortality across all occupational groups. Considering the clear opposite trend of the occupational gradient in incidence and survival, and the very low mortality, the finding of survival disparities in thyroid cancer might be partly due to overdiagnosis which first started among high SES women.

Although clinical factors such as stage at diagnosis and treatment are observed as the most important determinants of cancer survival social disparities, a number of studies found persistent SES disparities in survival even after adjusting for stage and treatment. ${ }^{12}$ Psychosocial factors associated with SES are also considered to play a role in cancer survival, for example, the impact of social support on breast cancer survival. ${ }^{36}$

Our findings with regard to occupational disparities on overall survival in women with cancer (all sites combined) are in line with previous findings in men in Korea; HR $1.38,95 \%$ CI 1.33 to 1.43 for service/sales workers, HR $1.45,95 \%$ CI 1.42 to 1.48 for blue-collar workers. ${ }^{7}$ There was no obvious difference between men and women on risk estimates in survival disparity in all cancer, although men had more cancer sites with statistically significant results. By contrast, occupational disparities in cancer incidence or mortality are more substantial in men than in women according to previous Korean studies. ${ }^{1011}$ These findings would seem to suggest that factors related to cancer survival, such as earlier detection and better treatment can be more important factors than factors related to cancer incidence-health behaviour (ie, smoking and alcohol) or occupational carcinogen exposure-for reducing cancer disparities among working women in Korea.

The present study had some strengths. First, using a large and representative workers cohort and cancer 
All Cancer

Lung

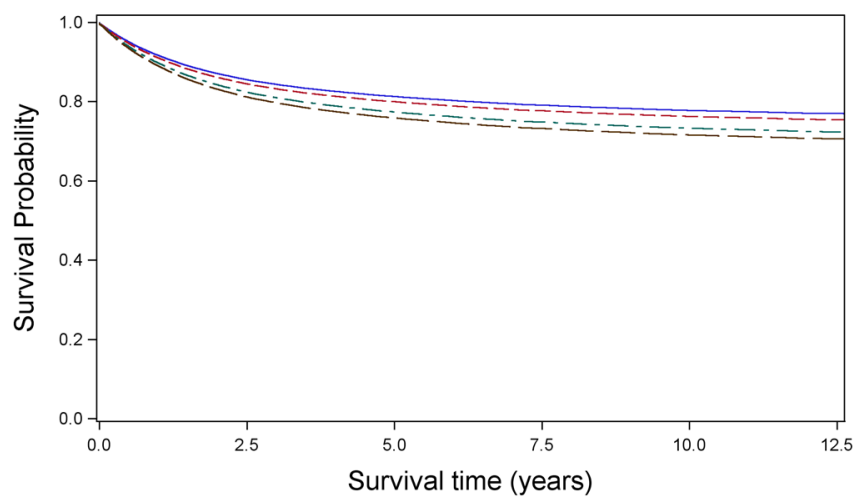

Breast

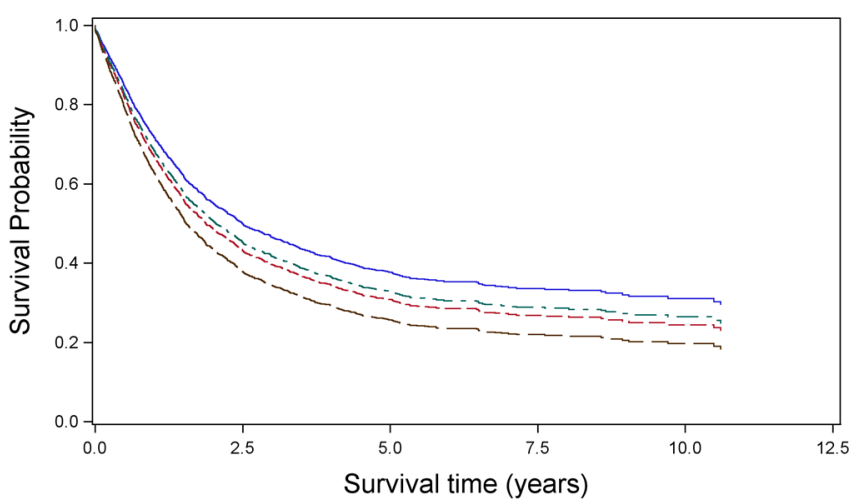

Cervix
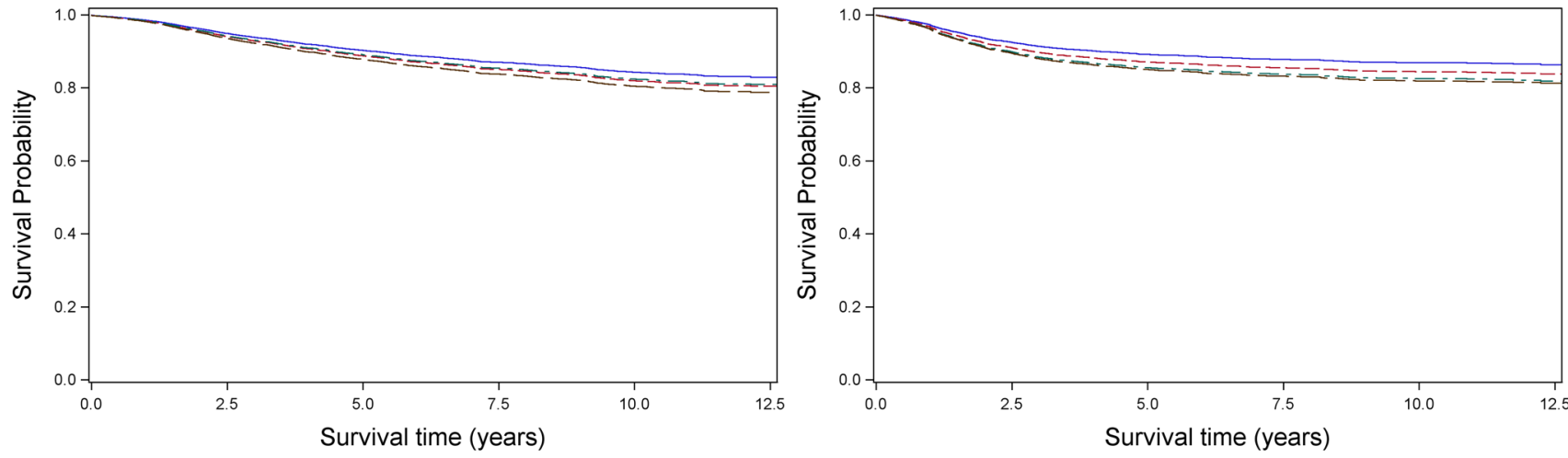

Thyroid

Non-Hodgkin lymphoma
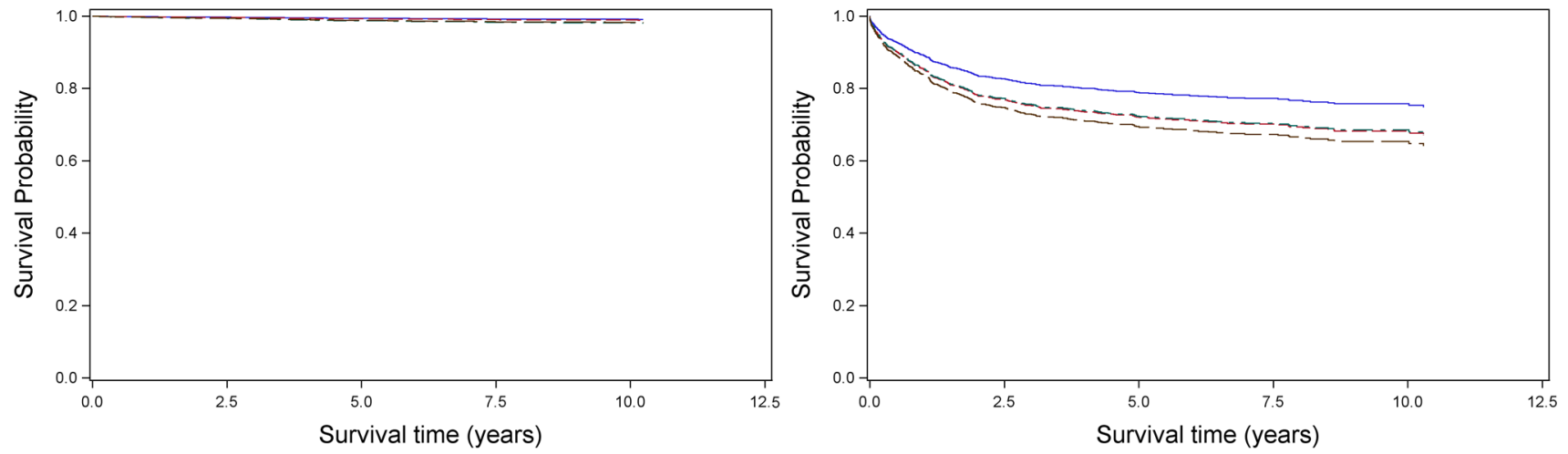

Occupational group

Managers, professionals and technical workers

\section{- - C Clerks \\ _ - - Service and sales workers}

- Blue-collar workers

Figure 2 Survival curves by occupational groups and selected cancer sites adjusted by age and year of diagnosis.

registry data enabled us to analyse a number of specific cancer sites with a sufficient number of cases. The database used for this study, the Employment Insurance data and the National Cancer registry are very complete; therefore, the findings of this study are generalisable to the population of working women in Korea. Second, due to our longitudinal follow-up design, we included only incident cases; hence, reverse causation (ie, cancer diagnosis resulting in a change in occupation) can be ruled out. Third, we classified occupations based on the 
information from the Employment Insurance data, which is determined by the companies hiring the individuals. This information is expected to be more accurate than the information collected by self-report.

This study also has several limitations. First, due to the lack of information on important covariates including a stage at diagnosis, treatment information, we could not evaluate the contribution of mediating variables between occupation and survival. Second, the occupational information was available only for 1995-2000; therefore, we could not consider the change of occupation after 2000. Also, the workers' data to match cancer registry were available for only the workers who held the same occupation between 1995 and 2000, hence the women who diagnosed with cancer before 2000 could not be selected in the study if they had changed occupation between cancer diagnosis and 2000. However, around $90 \%$ of study sample was diagnosed with cancer after 2000, and they were included in the analysis regardless of changing occupation after cancer diagnosis.

Our study sample did not include women who were not in paid employment. Female labour force participation rates were between $47.0 \%$ and $49.5 \%$ for all ages in Korea during 1995-2000, the period covered by our data. ${ }^{37}$ Thus, the results are not generalisable to all women in Korea. Furthermore, unemployed women and homemakers showed lower participation in cancer screening than employed women according to a previous study. ${ }^{30}$ Overall survival differences among cancer patients might be wider in the general population if we include unemployed women.

Even though we used large registry data, we did not perform subgroup analysis for rare cancer due to a small number of cases. Among the analysed cancer sites, corpus uteri and thyroid cancer showed relatively wide CI due to smaller number of patients or deaths.

In conclusion, we found substantial occupational disparities in overall survival among Korean working women with cancer, particularly in lung, breast, thyroid cancer and nonHodgkin's lymphoma. Further investigation to assess the influence of possible mediators between occupation and cancer survival is warranted. Health policies should enhance access to cancer screening and quality of treatment among patients with cancer with lower SES occupations.

Contributors $\mathrm{H}$-EL and E-AK conceived of the presented idea. $\mathrm{H}-\mathrm{EL}$ designed the study and performed statistical analysis. IK, E-AK and MZ participated in its design. $\mathrm{H}$-EL wrote the first draft of the manuscript. E-AK, MZ and IK critically revised the manuscript. All authors read and approved the final manuscript.

Funding The authors have not declared a specific grant for this research from any funding agency in the public, commercial or not-for-profit sectors.

\section{Competing interests None declared.}

Patient and public involvement Patients and/or the public were not involved in the design, or conduct, or reporting, or dissemination plans of this research.

\section{Patient consent for publication Not required.}

Ethics approval This study was approved by the institutional review boards of the Occupational Safety and Health Research Institute and Korea Occupational Safety and Health Agency (KOSHA), Ulsan, Korea. Approval no: COD-89.

Provenance and peer review Not commissioned; externally peer reviewed.
Data availability statement No data are available. The data using this study were obtained by combining the national cancer registry, death statistics, and Korean Employment Insurance system during the governmental investigation projects, which can not be in public.

Open access This is an open access article distributed in accordance with the Creative Commons Attribution Non Commercial (CC BY-NC 4.0) license, which permits others to distribute, remix, adapt, build upon this work non-commercially, and license their derivative works on different terms, provided the original work is properly cited, appropriate credit is given, any changes made indicated, and the use is non-commercial. See: http://creativecommons.org/licenses/by-nc/4.0/.

\section{ORCID iDs}

Hye-Eun Lee http://orcid.org/0000-0003-4648-5042

Eun-A KIM http://orcid.org/0000-0002-8582-234X

\section{REFERENCES}

1 Jung K-W, Won Y-J, Kong H-J, et al. Cancer statistics in Korea: incidence, mortality, survival, and prevalence in 2016. Cancer Res Treat 2019;51:417-30.

2 Rachet B, Woods LM, Mitry E, et al. Cancer survival in England and Wales at the end of the 20th century. Br J Cancer 2008;99(Suppl 1):S2-10.

3 Booth CM, Li G, Zhang-Salomons J, et al. The impact of socioeconomic status on stage of cancer at diagnosis and survival: a population-based study in Ontario, Canada. Cancer 2010;116:4160-7.

4 Kogevinas M, Porta M. Socioeconomic differences in cancer survival: a review of the evidence. IARC Sci Pub/ 1997;138:177-206.

5 Davey Smith G, Hart C, Hole D, et al. Education and occupational social class: which is the more important indicator of mortality risk? $\mathrm{J}$ Epidemiol Community Health 1998;52:153-60.

6 Zaitsu M, Kim Y, Lee H-E, et al. Occupational class differences in pancreatic cancer survival: a population-based cancer registry-based study in Japan. Cancer Med 2019;8:3261-8.

7 Lee H-E, Zaitsu M, Kim E-A, et al. Occupational class and cancer survival in Korean men: follow-up study of nation-wide working population. Int J Environ Res Public Health 2020;17. doi:10.3390/ ijerph17010303. [Epub ahead of print: 01 Jan 2020].

8 Zaitsu M, Lee H-E, Lee S, et al. Occupational disparities in bladder cancer survival: a population-based cancer registry study in Japan. Cancer Med 2020;9:894-901.

9 Ellis L, Woods LM EJ, et al. Cancer incidence, survival and mortality: explaining the concepts: incidence, survival and mortality. Int $J$ Cancer 2014;135:1774-82.

10 Lee H-E, Zaitsu M, Kim E-A, et al. Cancer incidence by occupation in Korea: longitudinal analysis of a nationwide cohort. Saf Health Work 2020;11:41-9.

11 Lee H-E, Kim H-R, Chung YK, et al. Mortality rates by occupation in Korea: a nationwide, 13-year follow-up study. Occup Environ Med 2016;73:329-35.

12 Quaglia A, Lillini R, Mamo C, et al. Socio-economic inequalities: a review of methodological issues and the relationships with cancer survival. Crit Rev Oncol Hematol 2013;85:266-77.

13 Woods LM, Rachet B, Coleman MP. Origins of socio-economic inequalities in cancer survival: a review. Ann Oncol 2006;17:5-19.

14 Carlsen K, Høybye MT, Dalton SO, et al. Social inequality and incidence of and survival from breast cancer in a population-based study in Denmark, 1994-2003. Eur J Cancer 2008;44:1996-2002.

15 Jang B-S, Chang JH. Socioeconomic status and survival outcomes in elderly cancer patients: a national health insurance service-elderly sample cohort study. Cancer Med 2019;8:3604-13.

16 Kwak M, Kim C. Effect of Area-Level deprivation on cancer survival time: a register-based follow-up study of 145585 Korean subjects. Asia Pac J Public Health 2018;30:19-28.

17 Yim J, Hwang S-S, Yoo K-Y, et al. Contribution of income-related inequality and healthcare utilisation to survival in cancers of the lung, liver, stomach and colon. J Epidemiol Community Health 2012;66:37-40

18 Kwak M, Kim C, Age Dby. Disparities by age, sex, tumor stage, diagnosis path, and Area-level socioeconomic status in survival time for major cancers: results from the Busan cancer registry. $J$ Korean Med Sci 2017;32:1974-83.

19 Choi IK, Hyun JJ, Kim SY, et al. Influence of socioeconomic status on survival and clinical outcomes in patients with advanced gastric cancer after chemotherapy. Oncol Res Treat 2014;37:310-4.

20 Jang JS, Shin DG, Cho HM, et al. Differences in the survival of gastric cancer patients after gastrectomy according to the medical insurance status. J Gastric Cancer 2013;13:247-54. 
21 Karjalainen S, Pukkala E. Social class as a prognostic factor in breast cancer survival. Cancer 1990;66:819-26.

22 Auvinen A, Karjalainen S, Pukkala E. Social class and cancer patient survival in Finland. Am J Epidemiol 1995;142:1089-102.

23 Murphy M, Goldblatt P, Thornton-Jones $\mathrm{H}$, et al. Survival among women with cancer of the uterine cervix: influence of marital status and social class. J Epidemiol Community Health 1990;44:293-6.

24 Link BG, Phelan J. Social conditions as fundamental causes of disease. J Health Soc Behav 1995;Spec No:80-94.

25 Jones CC, Mercaldo SF, Blume JD, et al. Racial disparities in lung cancer survival: the contribution of stage, treatment, and ancestry. $J$ Thorac Oncol 2018;13:1464-73.

26 Kim S-G, Hahm M-I, Choi K-S, et al. The economic burden of cancer in Korea in 2002. Eur J Cancer Care 2008;17:136-44.

27 Yoon TH, Lee S-Y, Kim C-W, et al. Inequalities in medical care utilization by South Korean cancer patients according to income: a retrospective cohort study. Int J Health Serv 2011;41:51-66.

28 Suh M, Song S, Cho HN, et al. Trends in participation rates for the National cancer screening program in Korea, 2002-2012. Cancer Res Treat 2017;49:798-806.

29 Choi E, Lee YY, Suh M, et al. Socioeconomic inequalities in cervical and breast cancer screening among women in Korea, 2005-2015. Yonsei Med J 2018:59:1026-33.

$30 \mathrm{Kim} \mathrm{J}-\mathrm{Y}$, Kang H-T. Association between socioeconomic status and cancer screening in Koreans over 40 years in age based on the
2010-2012 Korean National health and nutrition examination survey. Korean J Fam Med 2016;37:287-92.

31 Kweon S-S, Kim M-G, Kang M-R, et al. Difference of stage at cancer diagnosis by socioeconomic status for four target cancers of the National cancer screening program in Korea: results from the Gwangju and Jeonnam cancer registries. J Epidemiol 2017:27:299-304.

32 Tripodi D, Ferron C, Malard O, et al. Relevance of both individual risk factors and occupational exposure in cancer survival studies: the example of intestinal type sinonasal adenocarcinoma. Laryngoscope 2011;121:2011-8.

33 Kwong RC, Karagas MR, Kelsey KT, et al. Arsenic exposure predicts bladder cancer survival in a US population. World $\mathrm{J}$ Urol 2010;28:487-92.

34 Lamure S, Carles C, Aquereburu Q, et al. Association of occupational pesticide exposure with immunochemotherapy response and survival among patients with diffuse large B-cell lymphoma. JAMA Netw Open 2019;2:e192093

35 Ahn HS, Kim HJ, Welch HG. Korea's thyroid-cancer "epidemic"-screening and overdiagnosis. N Engl J Med 2014;371:1765-7.

36 Kroenke $\mathrm{CH}$. A conceptual model of social networks and mechanisms of cancer mortality, and potential strategies to improve survival. Trans/ Behav Med 2018;8:629-42.

37 Lee BS, Jang S, Sarkar J. Women's labor force participation and marriage: the case of Korea. J Asian Econ 2008;19:138-54. 